\title{
FLORESTA URBANA, SOLUÇÕES BASEADAS NA NATUREZA E PAISAGEM PLANEJAMENTO E PROJETO NA CIDADE DE SÃO CARLOS (SP)
}

\author{
Daniel Tonelli Caiche \\ Renata Bovo Peres \\ Luciana Bongiovanni Martins Schenk
}

\section{RESUMO}

A urbanização e os conflitos gerados com o meio ambiente se apresentam como uma das mais desafiadoras questões dos nossos tempos, gerando a necessidade da criação de novas e diferentes abordagens sobre o território urbano como Floresta Urbana, Serviços Ecossistêmicos, Sistema de Espaços Livres e Infraestrutura Verde e, mais recentemente, Soluções baseadas na Natureza. Contudo, a incorporação desses conceitos em instrumentos normativos, bases para implantação de políticas públicas, ainda é um grande desafio nas cidades da América Latina. Diante do exposto, o objetivo desse artigo foi discutir e apresentar o caso do município de São Carlos (SP), como uma experiência de planejamento de Floresta Urbana com base em SbN, que se estrutura a partir de um Sistema de Espaços Livres, moldado por bases legais. O método utilizado dividiu-se em três partes, sendo a primeira um resgate histórico-temporal da criação das legislações e das cartografias de planejamento da última década, a segunda analisa a articulação desses instrumentos e dessas cartografias e na terceira parte apresenta-se um processo de planejamento e projeto de Paisagem, baseado em um Sistema de Espaços Livres e de Infraestrutura Verde. Os instrumentos marcaram, sequencialmente, um histórico de conquistas, como a criação de Áreas de Proteção e Recuperação de Mananciais - APREM; Áreas de Interesse Ambiental - AIA; Faixas Verdes Complementares - FVC; Parques Urbanos e a proposta de um Sistema de Parques Municipais - SIPAM. Contribui-se, assim, para a construção de caminhos para um planejamento mais sistêmico, ancorado em processos de construção cultural que integrem diferentes agentes e que sejam pautados na noção de interesse público e nas relações mais próximas entre homem e natureza.

\section{Palavras-chave}

Soluções baseadas na Natureza (SbN); Planejamento urbano; Sistema de Espaços Livres; Floresta Urbana; Paisagem. 


\title{
BOSQUES URBANOS, SOLUCIONES BASADAS EN LA NATURALEZA Y
} PAISAJE

\author{
PLANIFICACIÓN Y PROYECTO EN LA \\ CIUDAD DE SÃO CARLOS (SP)
}

\author{
Daniel Tonelli Caiche \\ Renata Bovo Peres \\ Luciana Bongiovanni Martins Schenk
}

\section{RESUMEN}

La urbanización y los conflictos generados con el medio ambiente son uno de los temas más desafiantes de nuestro tiempo, generando la necesidad de crear nuevos y diferentes enfoques del territorio urbano como Bosque Urbano, Servicios Ecosistémicos, Sistema de Espacio Abierto e Infraestructura Verde y, más recientemente, Soluciones basadas en la naturaleza. Sin embargo, la incorporación de estos conceptos en instrumentos normativos, bases para la implementación de politicas públicas, sigue siendo un gran desafío en las ciudades latinoamericanas. Dado lo anterior, el objetivo de este artículo fue discutir y presentar el caso de la ciudad de São Carlos (SP), como una experiencia de planificación de un Bosque Urbano basado en SbN, que se estructura a partir de un Sistema de Espacios Abiertos, conformado por bases legales. El método utilizado se dividió en tres partes, siendo la primera una revisión histórico-temporal de la creación de legislación y cartografías urbanísticas de la última década, la segunda analiza la articulación de estos instrumentos y cartografías y la tercera parte presenta un proceso de planificación del paisaje. y diseño, basado en un Sistema de Espacios Abiertos e Infraestructura Verde. Los instrumentos que marcaron secuencialmente una historia de logros que van desde la creación de Áreas de Protección y Recuperación de Fuentes de Agua - APREM; Áreas de interés ambiental - AIA; Tiras verdes complementarias - FVC; Parques Urbanos y Sistema de Parques Municipales - SIPAM. Se espera que a partir de este artículo se vislumbren caminos para una planificación más sistémica, anclada en procesos de construcción cultural que integran diferentes agentes y que se guian por la noción de interés público y relaciones más estrechas entre el hombre y la naturaleza.

\section{Palabras-clave}

Soluciones basadas en la naturaleza; Sistema de espacio abierto; Bosque Urbano; Parque Urbano; Paisaje. 


\title{
URBAN FOREST, NATURE BASED SOLUTIONS AND LANDSCAPE PLANNING AND PROJECT IN THE CITY OF SÃO CARLOS (SP)
}

\author{
Daniel Tonelli Caiche \\ Renata Bovo Peres \\ Luciana Bongiovanni Martins Schenk
}

\begin{abstract}
Urbanization and the conflicts generated with the environment are one of the most challenging issues of our times, generating the need to create new and different approaches to urban territory such as Urban Forest, Ecosystem Services, Open Space System and Green Infrastructure and, more recently, Nature-based Solutions. However, the incorporation of these concepts in normative instruments, bases for the implementation of public policies, is still a great challenge in Latin American cities. Given the above, the aim of this article was to discuss and present the case of the city of São Carlos (SP), as an experience of planning an Urban Forest based on SbN, which is structured from a System of Open Spaces, shaped by legal bases. The method used was divided into three parts, the first being a historical-temporal review of the creation of legislation and planning cartographies of the last decade, the second analyzes the articulation of these instruments and cartographies and the third part presents a process of Landscape planning and design, based on a System of Open Spaces and Green Infrastructure. The instruments that sequentially marked a history of achievements ranging from the creation of Protection and Recovery Areas of Water Sources - APREM; Areas of Environmental Interest - AIA; Complementary Green Strips - FVC; Urban Parks and a System of Municipal Parks - SIPAM. It is hoped that from this article, paths for a more systemic planning can be glimpsed, anchored in cultural construction processes that integrate different agents and that are based on the notion of public interest and on closer relations between man and nature.
\end{abstract}

\section{Keywords}

Nature Based Solutions; Open space system; Urban Forest; Urban Park; Landscape. 


\section{INTRODUÇÃO}

O processo de urbanização e os conflitos gerados com o meio ambiente se apresentam como uma das maiores e mais desafiadoras questões dos nossos tempos. Em cidades do mundo todo são frequentes problemas relacionados às inundações urbanas, ilhas de calor, alteração nos regimes de águas pluviais, entre outros efeitos cada vez mais marcantes e agudos, muitas vezes associados ao processo das mudanças climáticas. Como agravante em relação à nossa realidade, de acordo com a publicação do relatório do Painel Intergovernamental sobre Mudanças Climática (IPCC, 2020), 35\% dos países mais vulneráveis estão localizados na América Latina (Peres \& Schenk, 2021).

Pesquisadores e profissionais de diversos campos disciplinares vêm se dedicando a compreender os efeitos da urbanização e seus diferentes impactos na alteração das paisagens e como esses aspectos podem promover uma sociedade mais justa e sustentável (Lafortezza \& Sanesi, 2020; Zhao et al., 2013).

Diante da complexidade do processo de produção de cidades, o Planejamento da Paisagem, se apoia em ideias difundidas a partir de diferentes campos disciplinares e práticas profissionais e tem a abordagem sistêmica como uma de suas premissas.

Os conceitos Soluções baseadas na Natureza (SbN); Floresta Urbana, Sistema de Espaços Livres (SEL), Infraestrutura Verde e Serviços Ecossistêmicos são ancorados em abordagens sistêmicas e vêm de diferentes campos do conhecimento (como ciências ambientais, ecologia da paisagem, arquitetura e urbanismo). (Escobedo, Giannico, Jim, Sanesi, \& Lafortezza, 2019; Santos, Maria Fernanda Nóbrega Enokibara, 2021).

Trabalhados de forma integrada, esses conceitos podem ajudar tanto a restaurar os processos ecológicos naturais nas cidades, de modo a mitigar os efeitos das mudanças climáticas, quanto impactar positivamente as experiências humanas de identidade, memória e convívio. Essas integrações foram ainda mais evidenciadas durante a pandemia COVID-19, pois se vislumbram mudanças de paradigmas nos estilos de vida e nos usos dos diferentes espaços das cidades (Macedo, Picavet, Oliveira, \& Shih, 2021).

Além da importância da articulação de princípios e diretrizes e do alinhamento entre campos disciplinares, a incorporação desses conceitos em instrumentos normativos, capazes de servir como suporte para implantação de políticas públicas, é um aspecto fundamental para a viabilidade das ações de planejamento e gestão.

Em cidades latinoamericanas e, algumas, brasileiras, esforços vêm 
sendo realizados no sentido de inserir princípios relacionados às $\mathrm{SbN}$ nas legislações e políticas públicas (Fraga, 2020; Herzog \& Rozado, 2019). A despeito desses esforços, a implementação desses instrumentos ainda é realizada de forma parcial e pouco articulada entre as instâncias administrativas.

O município de São Carlos, localizado na região central do estado de São Paulo, vem sendo reconhecido como um exemplo de iniciativa de gestão pública, que criou, em conjunto com universidades e sociedade civil, uma sequência de instrumentos normativos que permitem promover estratégias de Floresta Urbana com base em SbN, a partir do reconhecimento de um Sistema de Espaços Livres que funciona como suporte para projetos de Infraestruturas Verdes.

A intenção na criação desses instrumentos normativos, foi sobretudo, identificar e salvaguardar partes estratégicas do território, espaços livres de edificações, e as transformar em mecanismos permanentes de gestão municipal, pois esses espaços podem ser planejados e projetados como lugares que promovem a vida e a base da resiliência urbana em uma cidade que historicamente sempre sofreu com problemas de inundações urbanas, principalmente nas áreas centrais.

Diante do exposto, o objetivo desse artigo é discutir e apresentar o caso do município de São Carlos (SP), como uma experiência de implementação de Floresta Urbana com base em SbN, que se estrutura a partir de um Sistema de Espaços Livres e que dialoga com bases legais em suas formas municipais, estaduais e federais. A expectativa é que esse esforço desenvolva referências potenciais de planejamento e projeto e que possam ser adaptadas a contextos semelhantes.

\section{REFERENCIAL TEÓRICO}

As chamadas Soluções baseadas na Natureza (SbN), termo destacado pela União Internacional para a Conservação da Natureza, vêm ganhando protagonismo por ser uma forma de "trabalhar com a natureza", bem como um "conjunto de ações para proteger, gerenciar e restaurar os ecossistemas naturais ou modificados, e que atendem a desafios de forma sistêmica, eficaz e adaptativa, proporcionando, simultaneamente, benefícios de bem-estar e de biodiversidade" (Cohen-Shacham, Walters, Janzen, \& Maginnis, 2016, p.1).

Terminologia anterior e pioneira, a Floresta Urbana, também tem um caráter sistêmico em sua formulação, e pode ser entendida como o conjunto de todas as árvores existentes nas áreas urbanas e periurbanas de uma cidade, incluindo árvores presentes nas calçadas, estacionamentos, parques, bosques, praças, áreas verdes, áreas de preservação permanente e de áreas particulares. Atualmente, sua 
formulação compreende também tipologias contemporâneas, como edificações, paredes e telhados verdes (Cormier \& Pellegrino, 2008; Escobedo et al., 2019).

Por sua vez, e potencialmente relacionado ao ideário de Floresta Urbana, o Sistema de Espaços Livres (SEL), abrange todo espaço não ocupado por um volume edificado, cujos principais exemplos são: o conjunto das ruas, calçadas, praças e parques, bem como os terrenos e os espaços privados livres de construções (Magnoli, 2006). A ideia de se pensar os espaços livres sistemicamente vem sendo reconhecida como referência e base metodológica para se formular propostas de planejamento e desenhos que possam contribuir, com a conectividade, a biodiversidade e a qualidade ambiental e estética da paisagem, especialmente através da integração de infraestruturas e sistemas urbanos, com a valorização do uso público e de aspectos históricos e socioculturais ( Lima \& Schenk, 2018; S. S. Macedo, et al., 2012).

O conceito de Infraestrutura Verde é compreendido neste trabatho, dentro dos campos da Arquitetura, Urbanismo e Planejamento da Paisagem. Nesse sentido, ele não se refere apenas às estratégias integradas para manejo de águas pluviais, sendo um conceito mais abrangente, como definem Cormier e Pellegrino (2008, p. 128) como uma "rede de espaços interconectados, na escala do planejamento urbano e regional, composta de áreas naturais e outros tipos de espaços abertos que conservam os valores dos ecossistemas naturais e suas funções como mananciais, controle ambiental, regulação climática, recreação e lazer, provendo uma ampla gama de benefícios para a sociedade" (dos Santos \& Enokibara, 2021).

Infraestruturas Verdes são Soluções baseadas na Natureza com funções que podem ser ambientais (por exemplo, para conservação da biodiversidade), sociais (como o controle de drenagem em áreas urbanas) e econômicas (por exemplo, a valorização de imóveis), e que muitas vezes desempenham mais de uma função ao mesmo tempo (Instituto Polis, 2021).

Compreendendo que os conceitos podem ser trabalhados de forma integrada, os Serviços Ecossistêmicos aparecem como um importante ponto de convergência, pois eles são potencialmente capazes de quantificar e qualificar os espaços verdes através de indicadores, estabelecendo bases mais pragmáticas para processos de planejamento, projeto e decisões sobre o território urbano.(Bowler, Buyung-Ali, Knight, \& Pullin, 2010; Carrus et al., 2015; Mullaney, Lucke, \& Trueman, 2015).

São entendidos como os benefícios que as pessoas obtêm da natureza, ou seja, contribuições da natureza para as sociedades. Existem 
três categorias de Serviços Ecossistêmicos: de provisão (alimentos, plantas medicinais, madeira etc.), de regulação do ambiente feita pelos ecossistemas e pelos seres vivos (regulação do clima, controle da erosão, controle biológico de pragas), e os serviços culturais obtidos pelo contato entre humanos e natureza, com contribuição às relações sociais e culturais (como beleza cênica e de conservação da paisagem) (Instituto Polis, 2021).

Estes serviços têm, portanto, dimensões "objetivas" relacionadas ao controle das inundações urbanas, diminuição de temperatura e meIhoria da qualidade do ar; bem como dimensões "subjetivas", relacionadas à saúde física e mental, que podem dialogar com questões estéticas e culturais. (Gilstad-Hayden et al., 2015; Liu et al., 2018; Townsend \& Barton, 2018).

\section{MATERIAIS E MÉTODOS}

Visando apresentar e discutir a experiência do município de São Carlos (SP), o trabalho divide-se em três etapas metodológicas que se relacionam.

A primeira etapa foi a análise individual de alguns instrumentos de planejamento do município de São Carlos. Usando como procedimento a análise documental, cada legislação foi estudada, considerando a sequência histórico-temporal, permitindo visualizar e identificar aspectos que foram construindo, aos poucos, o Sistema de Espaços Livres, cujo processo de consolidação fundamentou a reserva de partes estratégicas do território aptas à implantação dos projetos de Floresta Urbana e SbN (Figuras 1 a 4).

A segunda etapa representou a análise integrada, utilizando procedimentos da cartografia complexa, e tratou do movimento de articulação dos instrumentos e das cartografias resultantes dessas legislações. A cartografia e sua sobreposição com diferentes informações como possível metodologia para a obtenção de áreas passíveis de ocupação são inauguradas no campo disciplinar da Arquitetura da Paisagem (lan McHarg). Seu livro Design with Nature se tornou referência para diferentes campos disciplinares e foi aprofundado pelo campo da Ecologia da Paisagem em relação às suas questões. Na atualidade vivenciam-se novas abordagens dessa metodologia, a partir do desenvolvimento técnico e tecnológico propiciado pelo uso de ferramentas georreferenciadas. Nessa etapa metodológica, os mapas resultantes de cada legislação foram cruzados por sistemas de informações geográficas, nos quais se procurou identificar espaços livres potenciais para intervenção, bem como elementos e características essenciais relativos à formação e consolidação de Floresta Urbana no município, considerando os princípios e abordagens das Soluções 
baseadas na Natureza (Figura 5).

Tomando como recorte espacial e potencial a Bacia Hidrográfica do Córrego do Simeão, fortemente prejudicada por inundações urbanas, a terceira etapa metodológica, desenvolveu workshop envolvendo leitura urbana, planejamento e projeto de Paisagem, considerando os instrumentos normativos analisados e o Sistema de Espaços Livres proposto para São Carlos. A partir do SEL, foram indicados cenários com propostas de Infraestruturas Verdes baseadas nos conceitos de Floresta Urbana e SbN.

O quadro a seguir (Quadro 1) apresenta a síntese metodológica do trabalho.

\section{Materiais e métodos}

\begin{tabular}{|l|c|c|c|c|}
\hline $\begin{array}{c}\text { Etapas } \\
\text { método- } \\
\text { lógicas }\end{array}$ & $\begin{array}{c}\text { Análise individual dos } \\
\text { instrumentos e cartografias } \\
\text { que constituem o SEL. }\end{array}$ & $\begin{array}{c}\text { Análise integrada dos } \\
\text { instrumentos e cartografias } \\
\text { que constituem o SEL. }\end{array}$ & $\begin{array}{c}\text { Aplicação em uma bacia } \\
\text { hidrográfica urbana } \\
\text { crítica de inundações }\end{array}$ \\
\hline $\begin{array}{c}\text { Procedi- } \\
\text { mentos } \\
\text { método- } \\
\text { lógicos }\end{array}$ & Análise documental & Cartografia complexa & $\begin{array}{c}\text { Projeto por cenários com } \\
\text { propostas de } \\
\text { infraestruturas verdes }\end{array}$ \\
\hline
\end{tabular}

Discutir e apresentar o caso do município de São Carlos (SP), como uma experiência de

implementação de Floresta Urbana com base em SbN, que se estrutura a partir de um Sistema de

Espaços Livres e que dialoga com instrumentos legais.

QUADRO 1. Síntese metodológica do trabalho.

Fonte: Elaboração própria.

\section{RESULTADOS E DISCUSSÃO: FLORESTA URBANA, SOLUÇÕES BASEADAS NA NATUREZA E PAISA- GEM NA CIDADE DE SÃO CARLOS (SP)}

\section{A construção das legislações e cartografias de Floresta Urbana}

São Carlos configura-se como uma cidade média paulista de relevância regional, localizada na porção centro-oeste do Estado de São Paulo. Possui uma extensão territorial de $1.136,9 \mathrm{~km} \square$, população estimada de 254.484 habitantes e densidade demográfica de 195,15 habitantes por kmø (IBGE, 2017). Além do critério populacional, os fatores que a caracterizam como uma cidade média de referência são: seu papel produtivo; sua articulação na rede urbana, localização em novos eixos de desenvolvimento (Sposito, 2006); presença de universidades e 
centros de pesquisas, o que a torna uma cidade conectada com redes globais de conhecimento e de inovação.

No que se refere ao seu Sistema de Espaços Livres há um cenário até então pouco qualificado, fragmentado e com baixa identidade pela população, principalmente, pelo histórico de desvalorização das políticas municipais (Peres, Silva, \& Schenk, 2019). Esse cenário tem comprometido a efetividade e a legitimidade de um planejamento, ancorado na noção de interesse público (Caiche \& Peres, 2021). Análises de Trevisan, Moschini, e Balzter, (2018) identificaram que as áreas de vegetação nativa no município de São Carlos reduziram cerca de $30 \%$ nos últimos dez anos e estão sendo substituídas, sobretudo, pela cultura da cana-de açúcar, acentuando o processo de fragmentação da paisagem. Em escala intraurbana, estudos de Viana (2013) indicam que $26 \%$ da área urbana são cobertos por vegetação arbórea, porém sua distribuição no território é irregular e desigual.

Reconhecendo a necessidade de tentativa de reversão desse cenário, as iniciativas desenvolvidas na cidade de São Carlos que serão descritas neste item, marcam um conjunto de conquistas demarcadas por instrumentos normativos em diferentes momentos históricos e gestões públicas.

O arcabouço normativo criado definiu instrumentos de planejamento e gestão diferenciados, que permitiram pensar estratégias associadas de promoção de Floresta Urbana. A intenção foi, principalmente, identificar e salvaguardar partes estratégicas do território e as transformar em mecanismos permanentes de gestão municipal para que pudessem estruturar um Sistema de Espaços Livres mais permanente e potencial de Floresta Urbana, como oportunidade de projeto dentro da perspectiva $\mathrm{SbN}$ e para o aumento da resiliência. Os instrumentos marcaram, sequencialmente, um histórico de conquistas, definidas sobretudo em legislação municipal, que vão, desde a criação de Áreas de Proteção e Recuperação de Mananciais - APREM; Áreas de Interesse Ambiental - AIA; Faixas Verdes Complementares - FVC; Parques Urbanos e a proposta de um Sistema de Parques Municipais.

O primeiro instrumento normativo foi o Plano Diretor Municipal, de 2005 (Lei Municipal no 13.691/2005). Esta peça representou o esforço de uma equipe de gestão que contemplou os instrumentos propostos pelo Estatuto da Cidade (Lei Federal 10.257/2001) e amparou-se em novas posturas de planejamento urbano e regionais. O esforço estava, portanto, em compor uma Secretaria de Habitação e Desenvolvimento Urbano e produzir informações sistematizadas sobre o município.

Essa equipe procurou realizar uma ampla análise do território a partir de suas características físicas, históricas, culturais e sociais, relações urbanas e rurais, e das integrações dessas dinâmicas. Nesse momento 
de descobertas e leituras, percebeunse o acentuado grau de transformações e impactos negativos advindos dos processos especulativos de ocupação do solo e que não contemplaram os elementos e as características presentes no município. Os impactos evidentes apontavam para a temática ambiental, sobretudo nas relações entre os processos inadequados de ocupação urbana e suas consequências, como ocupações irregulares em áreas de preservação, formação de áreas de risco à população, baixa qualidade das águas urbanas, pressão antrópica nos mananciais (Peres, 2012).

Uma grande vulnerabilidade evidenciada pela etapa de leituras técnicas e participativas relacionounse com as duas áreas de mananciais superficiais de abastecimento público: a Bacia do Rio Monjolinho e a Bacia do Ribeirão Feijão pelo fato de (principalmente a primeira) receberem um tipo de ocupação antrópica inadequada e, em momento algum, terem sido objeto de intervenções ou políticas públicas que almejassem protegêulas. A preocupação, nesse sentido, estava em evitar que essas áreas de mananciais deixassem de servir para o abastecimento público da população de São Carlos, procurando não repetir o que já tinha ocorrido com outra área de manancial, que foi rodeada pela ocupação urbana e, graças à poluição, foi inviabilizada.

A proteção dos mananciais marcou repercussões evidentes no Plano Diretor em termos de novas unidades de planejamento, como as bacias hidrográficas, por exemplo, e da definição de coeficientes e parâmetros construtivos diferenciados.

Além disso, em razão dessa demanda enfaticamente defendida pelo Conselho de Meio Ambiente (COMDEMA) da época, no ano seguinte, em dezembro de 2006, foi aprovado o segundo instrumento normativo, a Lei Municipal no 13.944/2006, que dispôs sobre a criação das Áreas de Proteção e Recuperação dos Mananciais do Município (APREMs), conhecida como Lei dos Mananciais.

Essa lei instituiu duas unidades de planejamento e gestão, cuja função social principal seria a preservação e a conservação do abastecimento de água com qualidade. As unidades criadas foram: APREM do Monjolinho e APREM do Feijão (Figura 1). Além desta importante demarcação territorial, o grande avanço, em termos de formação de Floresta Urbana foi a criação da chamada SAPRE 2 (Sub-área de Preservação 2). As SAPREs 2 representam áreas constituídas de uma faixa de 50 metros a partir das Áreas de Preservação Permanente definidas por Lei. As SAPREs ampliam em 70 metros as áreas de preservação permanente, tanto em cursos d'água quanto em nascentes, totalizando 100 e 120 metros as APP's respectivamente.

Análises de Capoia e Gonçalves (2019) verificaram que, entre 2006 e 2016, houve ganhos nas áreas de APP das bacias do Monjolinho e do 
Ribeirão do Feijão, sendo respectivamente 1,02\% e 9,41\%. Porém, ainda existem áreas em desacordo com a legislação, devido à expansão urbana e usos agrícolas, principalmente pastagem e solo exposto.

Dez anos depois da criação da Lei da APREM, no ano de 2016, o Plano Diretor Municipal passa por uma revisão (aprovado na Lei Municipal no 18.053/2016). Esse terceiro instrumento normativo, marca um importante avanço em relação à visibilidade e constituição do Sistema de Espaços Livres e em termos de um potencial planejamento da Floresta Urbana. Todo o conjunto de áreas de fundos de vale, nascentes, corpos d'água e Áreas de Preservação Permanente passam a ter relevante destaque enquanto elemento na paisagem, sendo classificado como Áreas de Interesse Ambiental (AIAs) (Figura 2).

As Áreas de Interesses Ambiental compreenderam, portanto, porções do território cujas funções sociais principais seriam: proteção de mananciais, nascentes e APPs; proteção da biodiversidade e de áreas com vegetação significativa ou reflorestamento de espécies nativas; proteção de praças, parques, paisagens notáveis, encostas e fundos de vale e uso adequado e sustentável; contribuição para a drenagem de água pluvial, prevenindo enchentes, erosões e promovendo a recarga dos reservatórios de águas subterrâneas; criação de Parques Lineares e Unidades de Conservação, como Parques Municipais e Estações Ecológicas; promoção da educação ambiental como ferramenta interdisciplinar para o reconhecimento, preservação e uso adequado dos recursos ambientais; promoção de ações necessárias para minorar, no nível local, os efeitos do aumento de temperatura associado às mudanças climáticas globais.

Juntamente com as AIAs, o Plano Diretor Municipal de 2016 também criou um novo importante instrumento de formação de Floresta Urbana, denominado Faixa Verde Complementar (FVC). As Faixas Verdes Complementares (FVC), são áreas contíguas às APPs, previstas para novos parcelamentos do solo, com dimensões que variam entre 10, 30 e 50 metros. Elas têm a finalidade de ampliar a faixa de proteção dos corpos d'água, incrementar a permeabilidade do solo, servir de suporte para a implantação de parques lineares e infraestruturas verdes e sistemas de drenagem sustentáveis.

De forma complementar aos instrumentos previstos nos Planos Diretores Municipais e na Lei dos Mananciais, o quarto instrumento normativo marca a criação de um conjunto de Parque Urbanos.

No ano de 2017, a gestão pública promove a criação de sete Parques Urbanos (Figura 3), representando o início da estruturação de um Sistema de Parques, que totalizou 232,91 hectares de áreas protegidas. Os Parques Urbanos, criados pelo Decreto Municipal no 170/2017, são áreas de domínio público, e dispõem de significativos fragmentos de 
vegetação, além de apresentarem características e potenciais.

As finalidades destes Parques, segundo o decreto, são: 1) proteção dos remanescentes da Mata Atlântica e Cerrado com o objetivo de assegurar a manutenção dos processos ecológicos; 2) realização de pesquisa científica e capacitação técnica visando orientar a proteção de remanescentes de vegetação nativa em áreas urbanas e periurbanas e a formação de corredores regionais de biodiversidade; 3) realização de atividades de educação ambiental visando difundir conceitos e estimular a adoção de práticas para a conservação ambiental e o uso sustentável de recursos naturais; e 4) uso público para atividades culturais e educacionais, recreação e lazer.

Para dar continuidade ao processo de planejamento e gestão, foi constituído no mesmo ano, no âmbito da Resolução no 01 do Conselho do Meio Ambiente de São Carlos - COMDEMA - o Grupo de Trabalho de Planejamento dos Parques Urbanos - GTPU. O GTPU é um coletivo multidisciplinar, que agrega gestão pública, universidades e movimentos sociais, sua abordagem teórico-metodológica tem na Paisagem e no Sistema de Espaços Livres um ponto de fundamental convergência. Seus principais objetivos são construir referências para sistemas de parques, espaços livres e de infraestruturas verdes, com projetos exemplares e instrumentos urbanísticos, que possam contribuir na redução de situações de riscos de eventos extremos, identificados como crescentes ameaças nessa tipologia de cidade.

Partindo do Decreto que criou os sete Parques Urbanos, o GTPU, foi estendendo a proposta para a constituição de um Sistema de Parques e Espaços Livres. A ação articulou os Parques definidos no Decreto a um sistema maior, que reuniu rede hídrica, áreas públicas, reservas periurbanas e mobilidade. A proposta foi discutida em apresentações públicas, com a participação de secretários municipais e diversos agentes (Schenk, Peres, \& Fantin, 2018). Este esforço coletivo mobilizou a formalização da proposta do SIPAM, considerado o quinto instrumento normativo que propõe a constituição de três categorias de parques municipais, sendo: Parques Urbanos, Parques Lineares e Parques Potenciais (Figura 4). 
FIGURA 1. (ESQ.) Cartografia das APREMs. A mancha verde menor indica a APREM do Monjolinho e a mancha verde maior indica a APREM do Feijão.

Fonte: Elaboração própria.

FIGURA 2. (DIR.) Cartografia das AlAs e FVCs.

Fonte: Elaboração própria.

FIGURA 3. (ESQ.) Cartografia dos

Parques Urbanos. As manchas verdes indicam os Parques Urbanos criados pelo Decreto Municipal no

170/2017.

Fonte: Elaboração própria.

FIGURA 4. (DIR.) Cartografia do SIPAM. Com base nos Parques Urbanos pelo Decreto Municipal no 170/2017, foram somados os Parques Lineares (manchas verdes contíguas aos rios urbanos) e os Parques Potenciais (manchas verdes periurbanas).

Fonte: Elaboração própria.
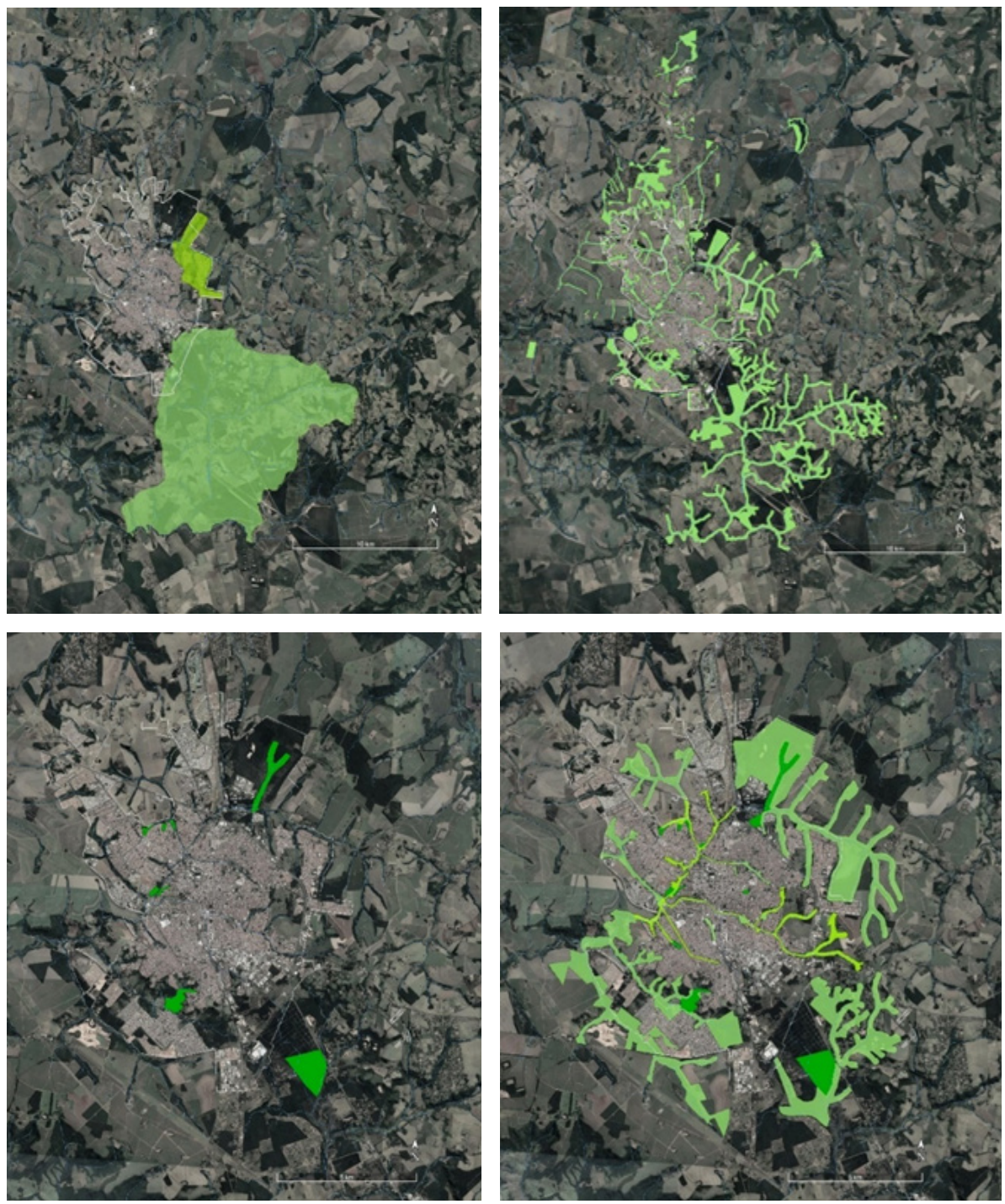

Em 2020, São Carlos recebeu um prêmio internacional, do Programa Tree Cities of the World, promovido pela Arbor Day Foundation e pela Organização das Nações Unidas para a Alimentação e a Agricultura (FAO), devido às boas práticas na gestão da vegetação urbana (Tree Cities of the World, 2020).

\section{Potenciais integrações dos instrumentos de planejamento na promoção da Floresta Urbana e de Soluções baseadas na Natureza}

Todas as ações descritas no item anterior representam, no contexto da cidade de São Carlos, avanços crescentes que buscaram constituir um arcabouço normativo de implementação de um Sistema de Espaços Livres, e que pudessem servir de peças estratégicas para a constituição da Floresta Urbana e de Soluções baseadas na Natureza, de forma contínua e permanente na gestão municipal.

O resultado é uma cartografia complexa que pode indicar ações e in- 
tervenções, no âmbito das Soluções baseadas na Natureza, e que são potencializadas a partir da promoção de instrumentos de Floresta Urbana (Figura 5).

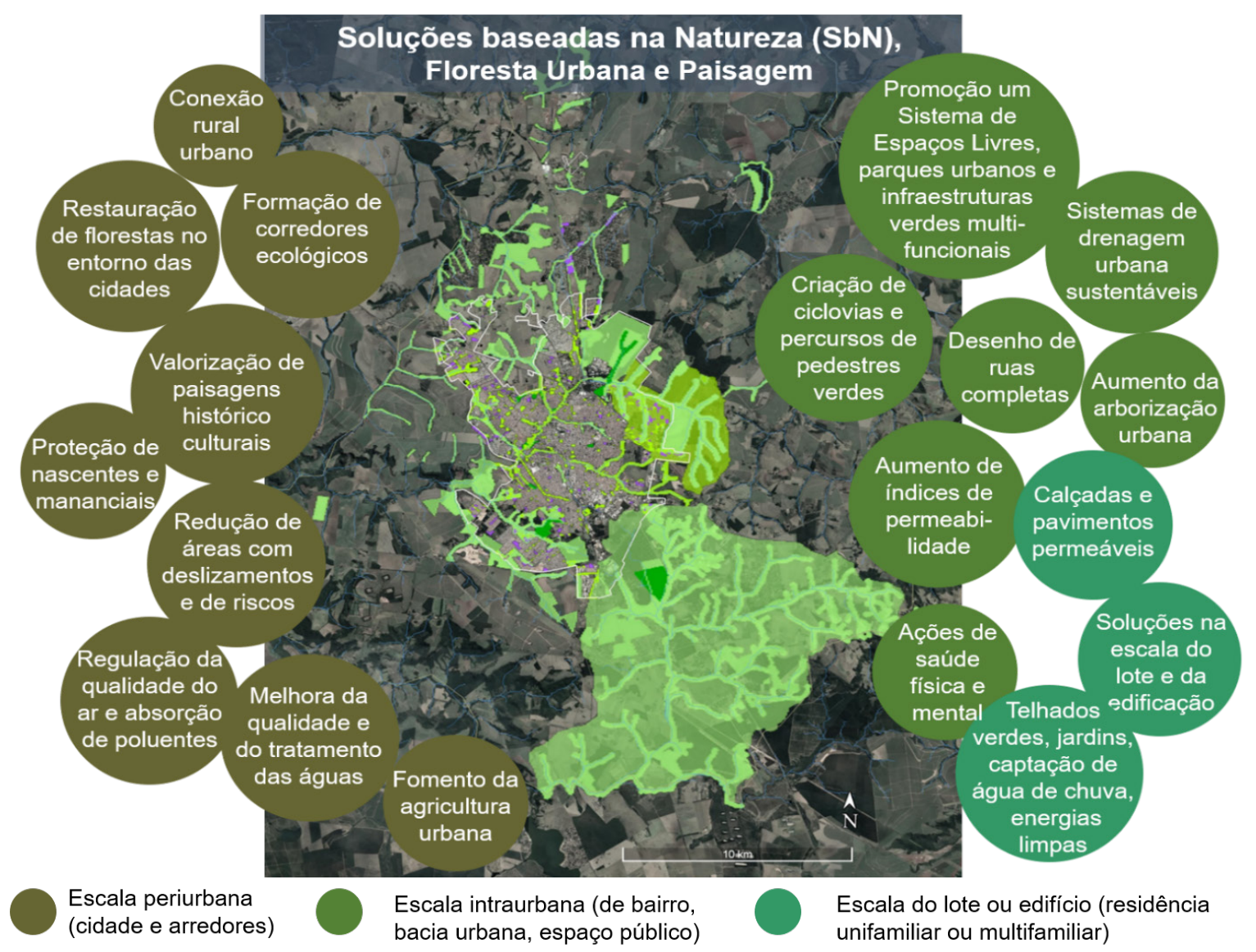

QUADRO 1. Figura 5: Cartografia complexa, que indica potenciais espaços livres para intervenção, bem como elementos e características essenciais relativas à formação e consolidação de Floresta Urbana no município de São Carlos, considerando os princípios e abordagens das Soluções baseadas na Natureza.

As cores representam as potenciais ações em diferentes escalas no domínio das SbN.

Fonte: Elaboração própria

(adaptado de: Projeto de investigação Nature4Cities ao abrigo do programa H2020 da EU, do Guia metodológico sobre SBN para adaptação climática local no País Basco e Herzog \& Rozado, 2019).

Com a integração dessa cartografia e instrumentos podem ser canalizadas propostas de diretrizes que buscariam aumentar ainda mais o controle do uso do solo visando a proteção ambiental, a mitigação de enchentes e a promoção de espaços de lazer, atividades educativas e culturais e convívio para as pessoas, potencializando Soluções baseadas na Natureza.

Essa efetividade se liga à produção não apenas de diretrizes, mas de planos e projetos que contemplem o desenho, por exemplo de vias que estruturam os territórios objetos de parcelamento, de forma que o sistema de espaços livres possa ser reconhecido. Essa ação, que procuraria distinguir nas glebas potenciais parques, praças e vias arborizadas, funcionaria assim, como elemento norteador dos futuros empreendimentos, ao mesmo tempo, garantiria espaços para construção de uma estratégia de resiliência para a cidade.

Entretanto, para que se constituam enquanto instrumento de planeja- 
mento de ordenamento do território, complementar ao zoneamento, alguns desses instrumentos, como as Áreas de Interesse Ambiental e as Faixas Verdes Complementares devem ainda passar por regulamentação específica, indicando normas especiais de parcelamento e diretrizes quanto ao uso e ocupação do solo.

\section{Floresta Urbana, SbN, Sistema de Espaços Livres e Infra- estruturas Verdes em uma bacia hidrográfica urbana de São Carlos}

Em novembro de 2020 uma chuva torrencial, com grande volume de água em curto espaço de tempo, provocou uma enchente de grande magnitude na área central da cidade de São Carlos. Os alagamentos não são raros nessa parte do território urbano e a imprensa os repercute desde a década de 30 do século passado. Contudo, esses eventos se tornaram mais comuns e dramáticos com a crescente impermeabilização das várzeas e encostas realizada ao longo dos anos, somados às mudanças climáticas.

O córrego do Gregório que cruza o centro da cidade foi sendo canalizado e esse processo foi acompanhado da supressão de árvores presentes nas ruas vizinhas. O que se pode perceber, em reflexão alicerçada pela literatura (SPIRN, 1985), é que os conflitos presentes foram construídos pelas escolhas do passado.

A relação entre os rios e córregos de uma cidade e sua arborização é uma questão inseparável em territórios urbanos que se pretendem saudáveis e preparados para um futuro de alterações climáticas nos quais eventos como a chuva mencionada tendem a ocorrer com maior frequência. A arborização urbana participa desse ideário de saúde e resiliência, pois além de contribuir para a saúde de sua população, diminuindo a temperatura e melhorando a qualidade do ar, ela tem um papel estratégico em relação à qualidade da água e à qualidade da experiência urbana que se pode vivenciar.

A bacia hidrográfica do Córrego do Simeão (Figura 6), que tributa suas águas no Córrego do Gregório na área central, foi referenciada pela imprensa como a grande causadora da tragédia (sic) de novembro de 2020 (Figura 7).

Buscando oferecer alternativas, a partir de uma perspectiva contemporânea de planejamento e projeto, professores e alunos das Universidades de São Paulo e Federal de São Carlos, se reuniram em um workshop que teve a duração de duas semanas e que também contou com a participação de especialistas voluntários. 

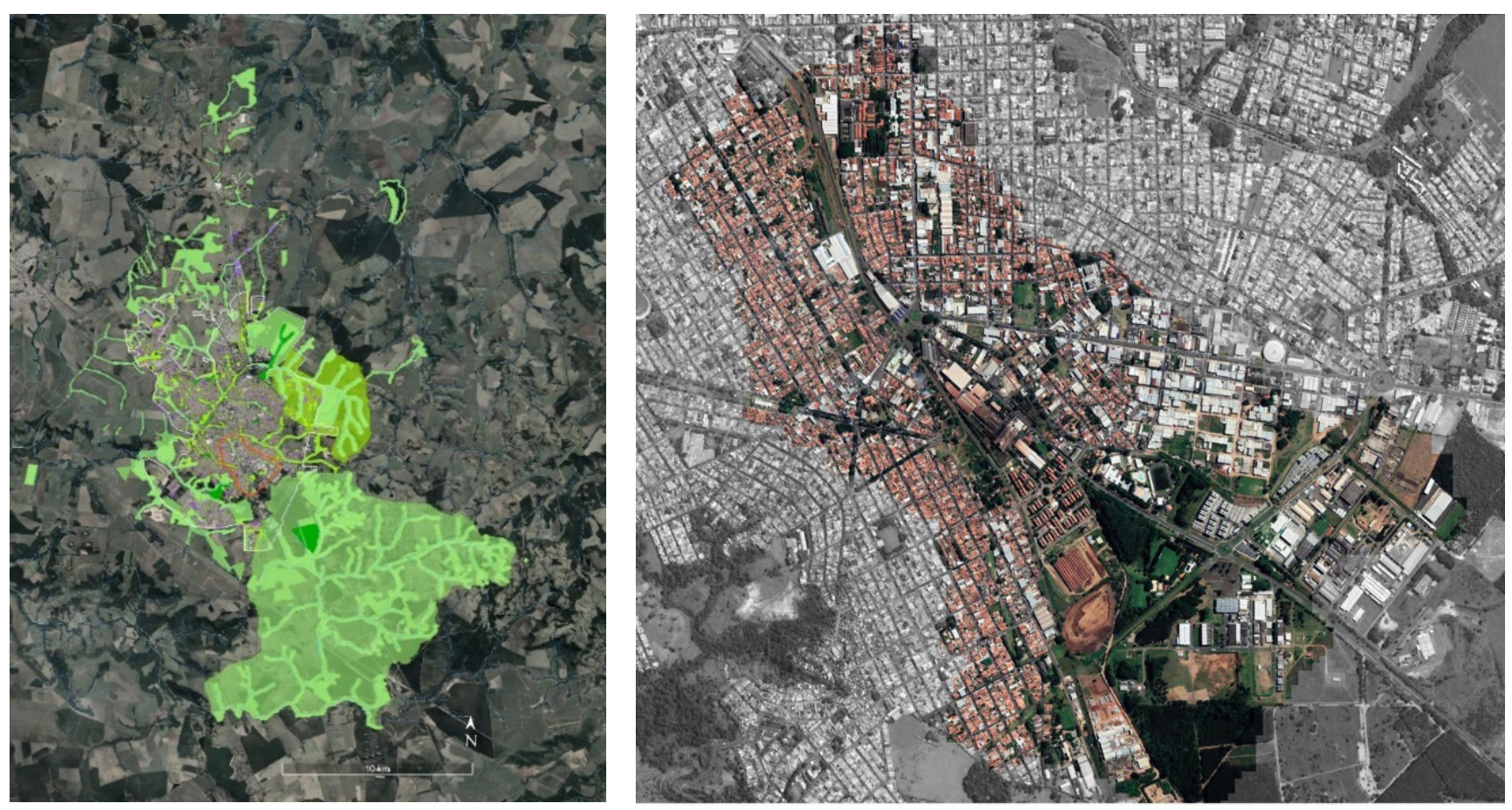

FIGURA 6. Destaque da Bacia Hi-

drográfica do Córrego do Simeão,

área de planejamento e projeto.

Fonte: Elaboração própria.
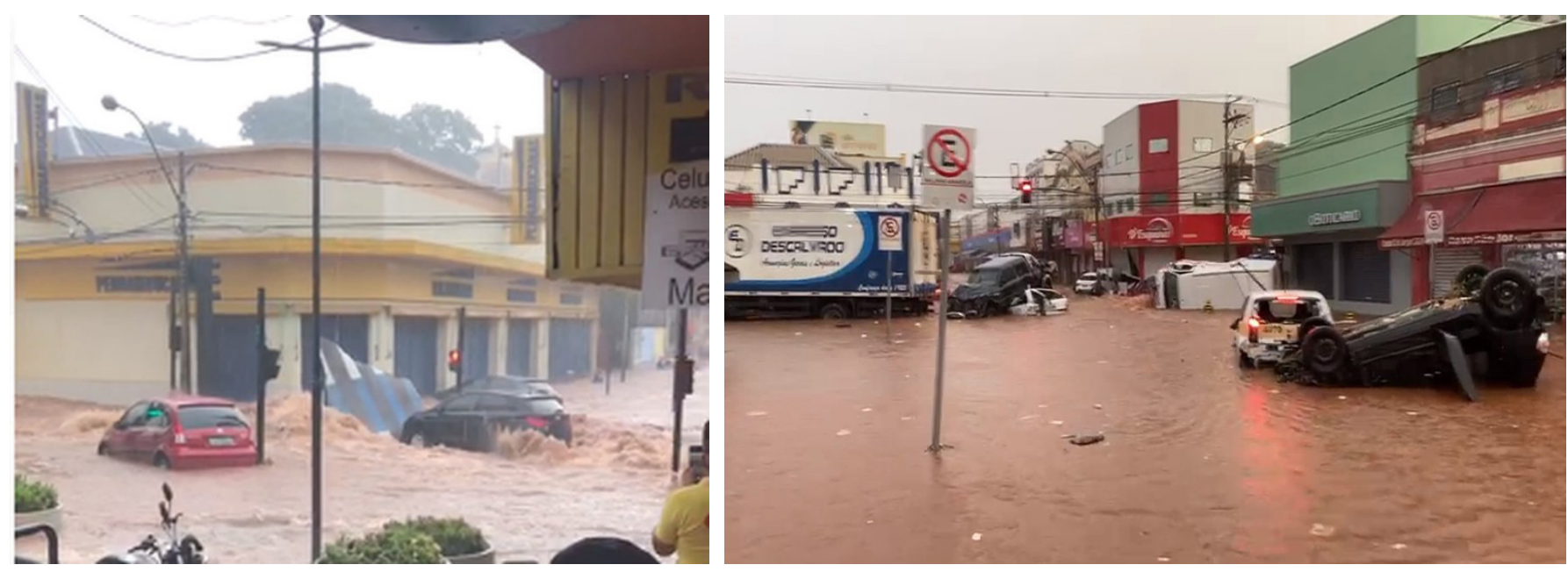

FIGURA 7. Imagens que ilustram

o evento da cheia de novembro de

2020. São Carlos, SP.

Fonte: https://g1.globo.com/sp/sao-carlos-regiao/noticia/2020/11/26/ chuva-com-granizo-causa-alagamentos-e-arrasta-veiculos-no-centro-de-sao-carlos.ghtml 
A estratégia de planejamento do grupo teve como motor a Paisagem em suas dimensões objetivas e subjetivas, através de leituras de dados e informações, cartografias e trabalho de campo, bem como fotografias e diálogo com líderes comunitários locais. A ação buscou identificar uma rede de espaços qualificados, diminuindo os conflitos causados pelo processo de ocupação humana em relação ao meio ambiente. Tomando como base os princípios da drenagem em bases mais naturalizadas, entre os produtos finais do workshop estavam a indicação de propostas de Infraestruturas Verdes, a identificação da presença de lugares permeáveis, bem como a arborização urbana pensada sistemicamente como Floresta Urbana.

A cultura brasileira em relação à drenagem urbana ainda se apoia sobre pressupostos da engenharia cinza: canalizar, tamponar e levar a água rapidamente de um lugar ao outro (Silva \& Porto, 2003). Contudo, planejar e projetar em um contexto como o das cidades brasileiras é, antes de tudo, compreender a necessidade de construir esse caminho de convivência entre técnicas, cinza e verde e ruptura com o preconceito em relação às soluções verdes. A disposição de planejamento da paisagem a partir dos pressupostos contemporâneos aqui explorados procura propor alternativas ao modo como pensamos o desenvolvimento, argumentando por novos pressupostos que estejam alinhados a leis que garantam sua efetividade.

Desse modo, a experiência do workshop mirava a oportunidade de apresentar soluções e lugares exemplares, contribuindo nesse esforço de alteração de uma cultura. A composição de um sistema de espaços livres a partir do recorte da Bacia Hidrográfica é composto de parques, praças, ruas e avenidas arborizadas constituindo uma rede verde em contato e interação com a rede azul configurada pela água em seus diversos registros.

A reunião de professores de diferentes formações criou um espaço interdisciplinar de debate trazendo desafios e riqueza ao processo. $\mathrm{O}$ grupo visualizou nessa demanda a oportunidade de inscrever os espaços livres da cidade em uma agenda contemporânea ligada à novas paisagens. Os princípios que nutrem o GTPU que se reúne a esse processo se pautam em valores inaugurados pelo campo disciplinar da Arquitetura da Paisagem e que ganham novo fôlego a partir do desenvolvimento das chaves de pesquisa como as de Floresta Urbana, e prática contemporâneas como as de Infraestrutura Verde e Soluções Baseadas na Natureza.

Uma das estratégias metodológicas desenvolvidas pelo GTPU é a construção de cartografias, inspiradas nos estudos de lan McHarg (2000), sendo a reunião de diferentes cartografias através de geoprocessamento, o que permite o cruzamento de dados e geração de informações. Essa atualização da metodologia inaugurada na década de 
60 do século passado já vem ocorrendo em campos como a ecologia da paisagem.

Um conjunto de cartografias sínteses foram produzidas (como as apresentadas nas Figuras 8 e 9), reunindo informações como hidrografia, relevo, áreas livres públicas de lazer, áreas de proteção ambiental garantidas por Lei, perímetro urbano e áreas livres não qualificadas que foram destinadas a futuros parques pelo decreto Municipal de 2017.

Essas cartografias buscaram construir uma representação que reunissem espaços livres significativos para o estabelecimento de um sistema que pudesse configurar uma rede de Infraestrutura Verde na bacia. Essa ação torna visível potenciais áreas que podem ser incluídas no processo de planejamento. Estrategicamente neste momento procura-se unir os espaços que sejam públicos ou que, mesmo sendo privados, devem permanecer livres, sem ocupação de edificações, por serem protegidas por lei.

O workshop ocorreu durante duas semanas entre janeiro e fevereiro de 2021, com uma terceira semana de pós-produção de imagens, contando com a participação de 15 pessoas entre estudantes e professores. Seu desenvolvimento procurou produzir um processo de reflexão crítica e estratégia metodológica multiescalar a partir do recorte da Bacia Hidrográfica do Córrego do Simeão que permitisse visualizar o percurso entre o planejamento e os projetos, tendo como desafio a constituição de potenciais cenários a partir da realidade do lugar.

O primeiro movimento iniciou-se através de leituras do território que reuniu aportes objetivos como coleta de dados censitários e geoprocessamento para caracterização da área. A bacia contempla além do uso comercial à jusante, usos residenciais e mistos em sua porção média e residências e industriais à montante. Há marcadores de vulnerabilidade social e ambiental por toda a bacia, com a presença de um perfil de baixa escolaridade e renda. 

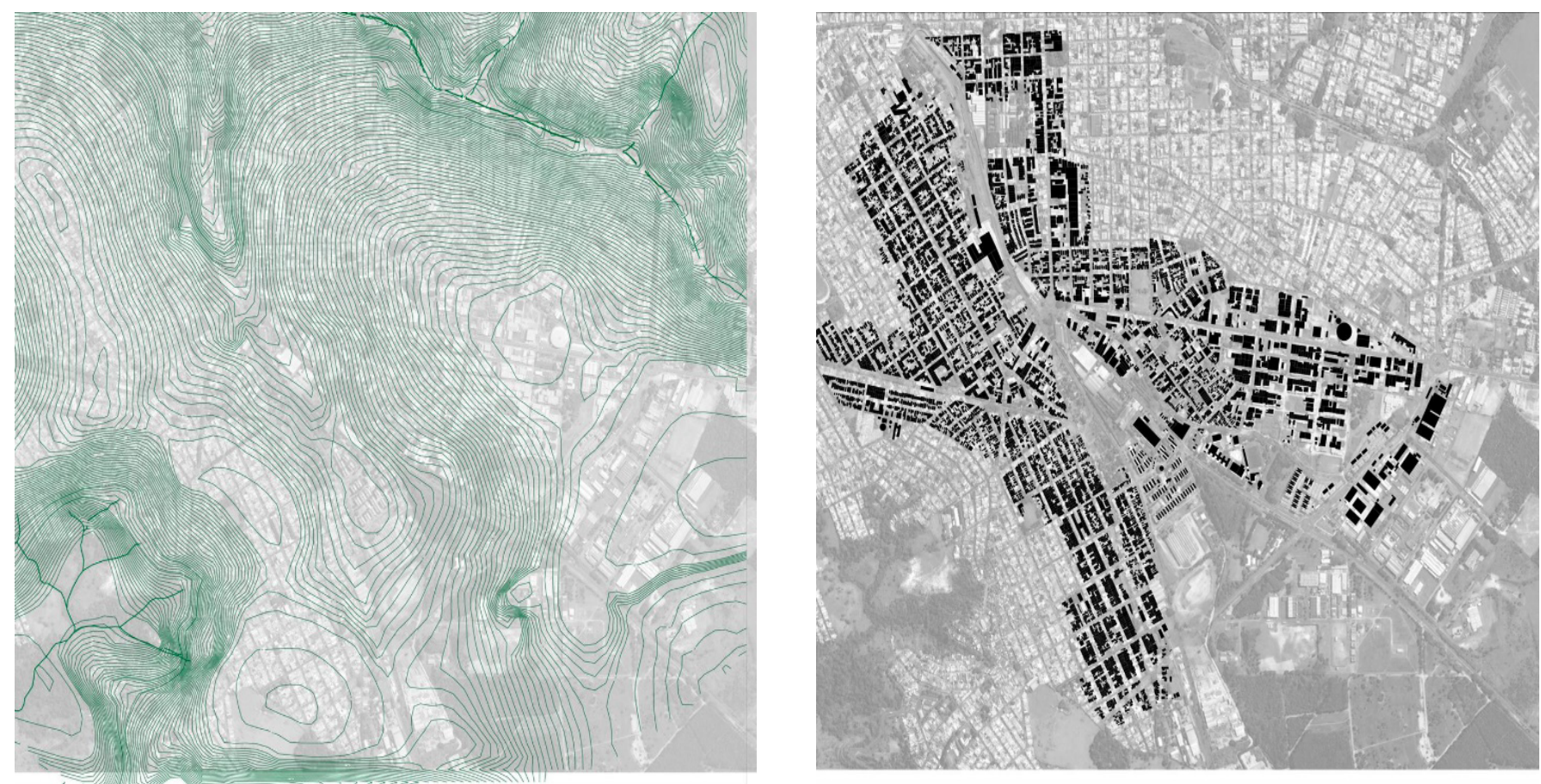

FIGURA 8. Bacia do Córrego do Simeão: curvas de nível.

Fonte: Elaboração própria

FIGURA 9. Bacia do Córrego do Simeão:áreas contruídas e impermeabilizadas.

Fonte: Elaboração própria
A passagem da linha férrea, atualmente apenas para o transporte de cargas, é uma presença marcante, dividindo a bacia em duas porções de terra desiguais. A estrutura de ruas segue o padrão das cidades brasileiras no qual o aspecto final é um mosaico de peças justapostas, uma vez que o processo de parcelamento se realiza a partir da iniciativa privada, muitas vezes comprometendo a continuidade de ruas e fragmentando o tecido urbano.

O segundo movimento se concentrou em conhecer a bacia com maior grau de proximidade. Em condições normais esse momento se denomina palmilhar o território, e parte da ideia de que a frequentação do lugar é condição necessária para a apreensão de suas qualidades. Aporte metodológico consolidado em pesquisas de matriz fenomenológica, esse caminhar compõe o processo de construção de inteligibilidade de um território fundamentado no corpo e sua experiência do lugar.

Para contornar a questão da impossibilidade de realização desse caminhar, por estarmos em condições de afastamento social, (COVID-19), escolhem-se duas alternativas: a primeira fazendo uso do recurso remoto, Google Street View, realizada pela maior parte do grupo que não estava na cidade de São Carlos por ocasião do workshop. E uma segunda, preenchendo lacunas e fazendo aquilo que se chamou palmilhar com pés alheios. Nesse momento, guardadas as devidas precauções, os integrantes que foram a campo de fato puderam ter contato com os líderes da comunidade organizada dos bairros que compõe a bacia hidrográfica (Figura 10). 


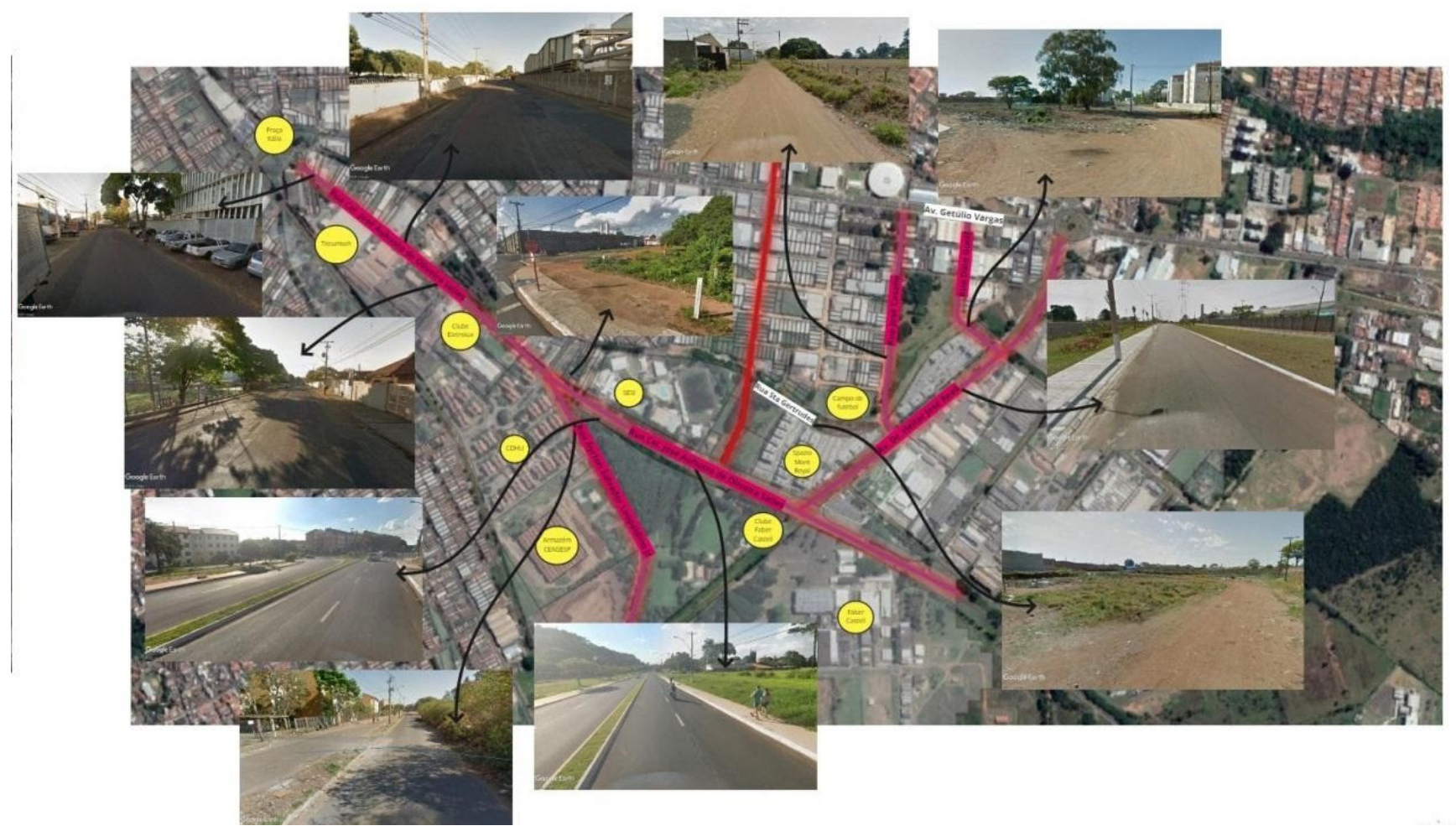

FIGURA 10.

Mapas de leituras realizados durante o Workshop USP Municípios / GTPU.

Fonte: Elaboração própria.
As imagens a seguir mostram os resultados alcançados ao longo das intensas semanas de trabalho.

Um Sistema de Espaços Livres, que reúne ruas arborizadas, praças e parques foi proposto para o território da bacia. A elaboração desse sistema se faz a partir das prerrogativas da Infraestrutura Verde, e é norteado pelo ideário da Floresta Urbana e SbN, mantendo estreito contato com a realidade da cidade de São Carlos. O horizonte é a constituição de novas paisagens para os bairros e moradores da $\mathrm{Ba}-$ cia do Simeão. Vários sistemas de retenção são pensados como peças técnicas que diminuem a velocidade e aumentam a possibilidade de infiltração da água pluvial, ao mesmo tempo, articulam espaços livres de lazer, encontro e fruição para a população da cidade (Figura 11). 


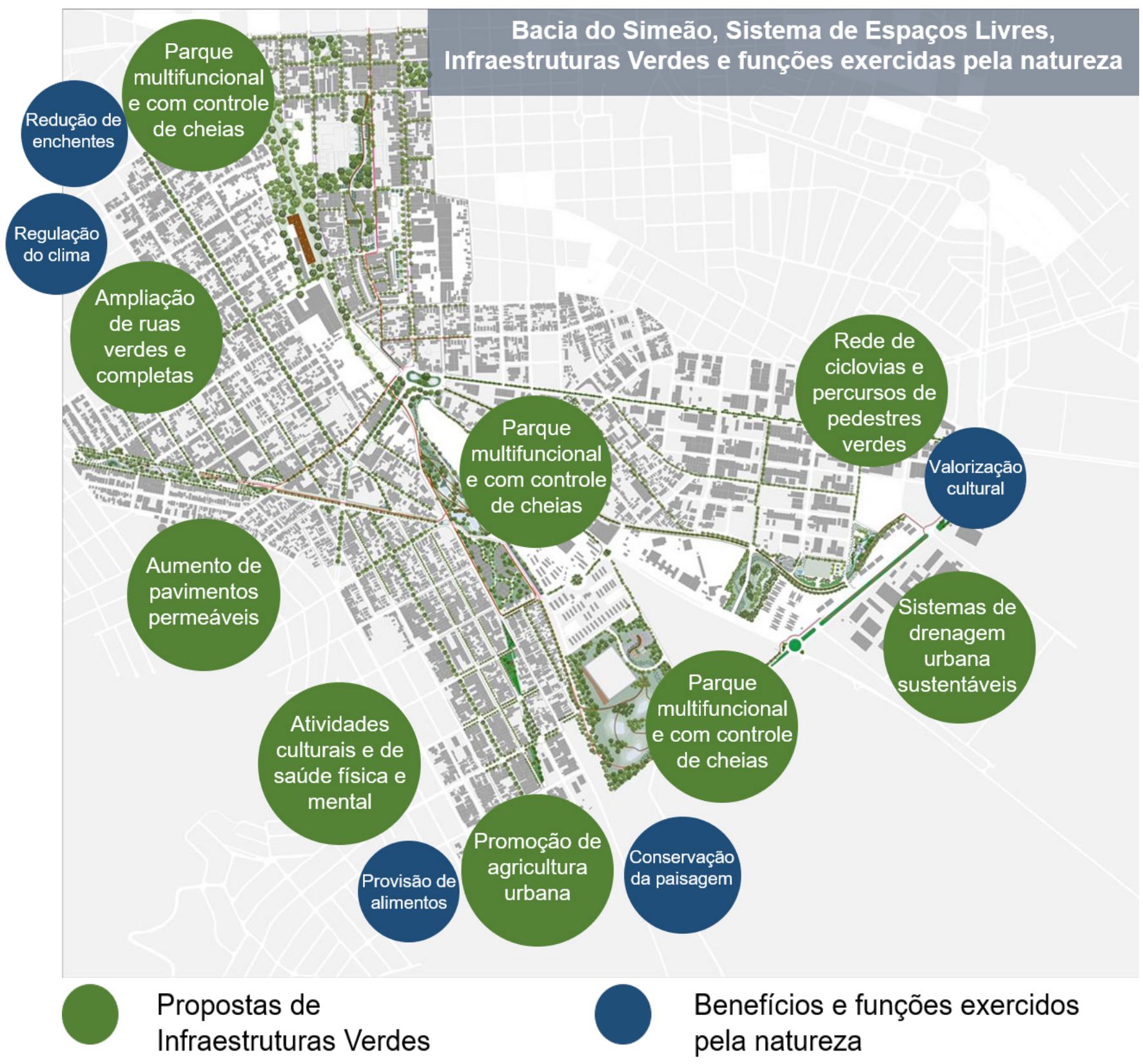

FIGURA 11.

Bacia do Simeão, SEL e Infraestruturas Verdes propostas (em verde) e algumas funções exercidas pela natureza (em azul). Imagem produzida no Workshop USP Municípios /

GTPU, 2021.

Fonte: Elaboração própria
O Sistema de Espaços Livres e as formas propostas apresentam novas paisagens materializadas como Infraestrutura Verde e pautadas pelo ideário das SbN, são lugares da brincadeira, do jogo, da vida ao ar livre. Uma memória que resgata os meandros dos rios, trapiches de madeira onde se realiza a pesca e o nado, o lugar de encontro com a natureza, fauna e flora bastante ausente das cidades brasileiras. A tradução desse imaginário para os desenhos foi um rico processo, cujo detonador foi justamente a paisagem de ausência e pouco significado encontrada.

O resultado final é uma alternativa que pretende funcionar como contraponto ao modelo de cidade existente. O desenho apresenta um Sistema de Espaços Livres verdejados numa proposta de geração de 
territórios mais resilientes e capazes de, através de suas paisagens, compor o imaginário e participar da vida de sua população. A expectativa é que esses desenhos possam participar dos debates acerca das soluções para o problema das enchentes e do futuro do centro da cidade de São Carlos.

A resposta que se ensaia nesse trabalho diz respeito a um repertório presente na maior parte dos brasileiros: a natureza está fora das cidades e, quando a natureza no urbano se manifesta, tem o registro do desastre. Inverter essa lógica de percepção é recriar a congruência, é reconstruir o encontro com a natureza em novas bases: técnica, estética e ética (Calliari, Staccione, \& Mysiak, 2019) (Figura 12).

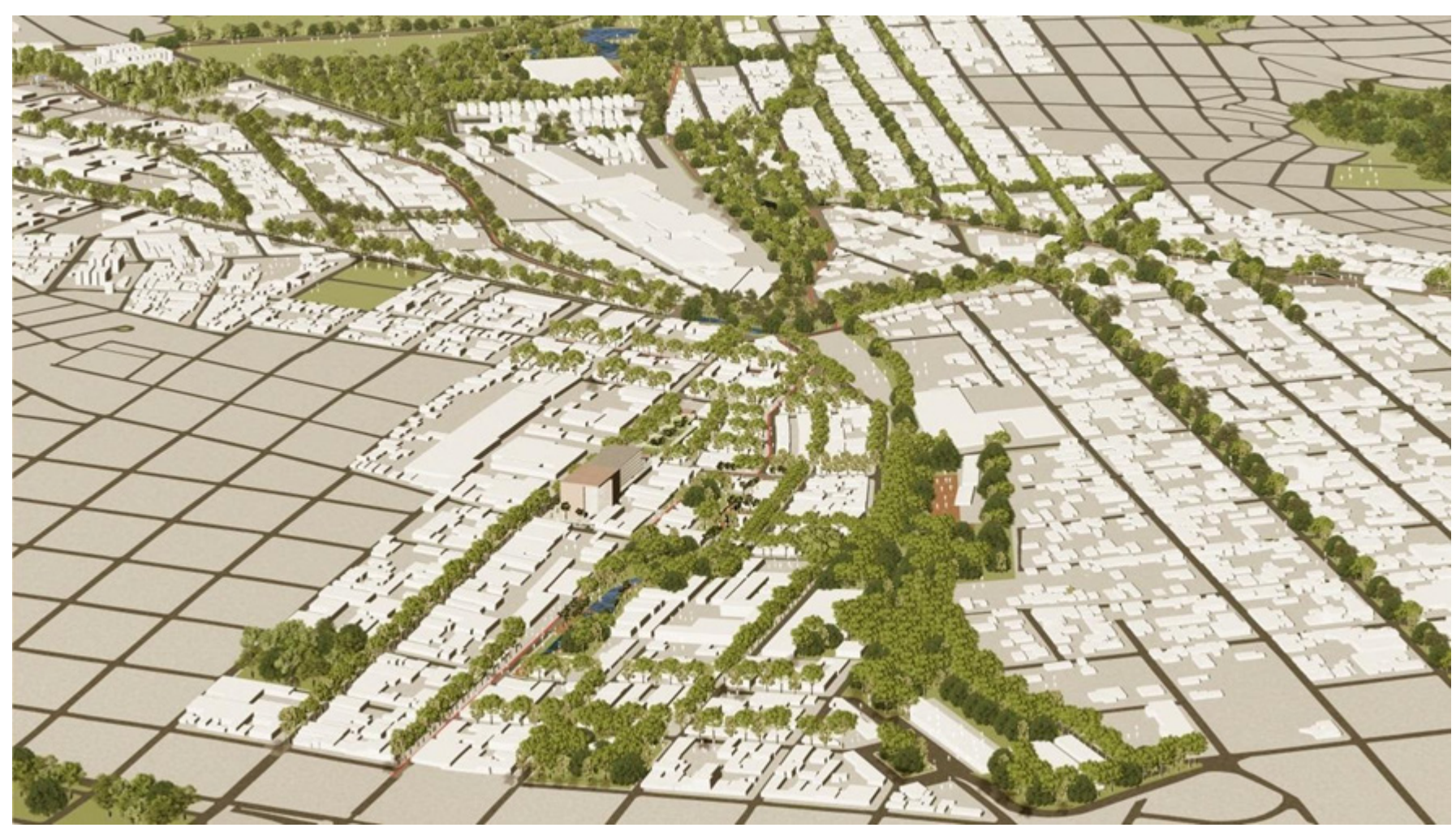

FIGURA 12.

Bacia do Simeão e o Sistema de Espaços Livres proposto. Imagem produzida no Workshop USP Municípios / GTPU, 2021. Fonte: Elaboração própria

\section{CONSIDERAÇÕES FINAIS}

Nas últimas décadas alterações de perspectivas relacionadas aos modos de intervenção nas cidades, baseadas em abordagens ecossistêmicas constituídas através de redes de espaços verdes multifuncionais, vem sendo cada vez mais observadas e reivindicadas.

A ideia de ampliar a complexidade dessas soluções contemporaneamente, nos leva a pensar não mais isoladamente, mas sim, nas relações "entre" conceitos, campos disciplinares, soluções, planejamento e projeto. Desse modo, o pensar "entre" estruturou o desenvolvimen- 
to desse artigo, que pretendeu, a partir do caso do município de São Carlos, contribuir com o debate sobre as relações entre espaços livres arborizados e permeáveis e que podem ser designados como partes da Floresta Urbana.

Apresentou-se uma experiência do processo de reflexão de um Sistema de Espaços Livres Verdes, para futura implantação de Soluções baseadas na Natureza (SbN), e a existência de lugares de lazer e preservação, sob uma dimensão dos serviços ecossistêmicos, considerados estratégicos na concepção dos espaços urbanos. Tudo isso, articuladas a corpos legais para aumentar a probabilidade de sua efetividade.

Esperávamos assim, que a resposta técnica contemplasse não apenas um registro mais naturalizado, agregando os benefícios dessa opção, mas especialmente que as soluções possam trazer à população uma experiência urbana de maior intensidade social e cultural, tais como pertencimento, referência, identidade e memória, envolvidos em uma ação transversal.

Se, até então, a grande lacuna na maioria das cidades brasileiras tem sido a construção de uma morfologia urbana, configurada em caráter aleatório e fragmentada, prevalecendo decisões calcadas, sobretudo, nos interesses do mercado imobiliário, talvez a articulação e construção de instrumentos normativos e projetos como esses apresentados nesse artigo, possam vislumbrar caminhos para um planejamento mais sistêmico, pautados na noção de interesse público e nas relações mais próximas entre homem e natureza.

\section{REFERÊNCIAS}

Bowler, D. E., Buyung-Ali, L., Knight, T. M. \& Pullin, A. S. (2010). Urban greening to cool towns and cities: A systematic review of the empirical evidence. Landscape and Urban Planning, 97(3), 147-155. https://doi.org/10.1016/j.landurbplan.2010.05.006

Caiche, D. T., \& Peres, R. B. (2021). A PRODUÇÃO NORMATIVA SOBRE ARBORIZAÇÃO URBANA NA CIDADE DE SÃO CARLOS (SP). Revista Brasileira de Arborização Urbana, 16(1), 51-65. https://doi.org/http://dx.doi.org/10.5380/revsbau. v16i1.76930

Calliari, E., Staccione, A. \& Mysiak, J. (2019). Science of the Total Environment An assessment framework for climate-proof nature-based solutions. Science of the Total Environment, 656, 691-700. https://doi.org/10.1016/j.scitotenv.2018.11.341

Carrus, G., Scopelliti, M., Lafortezza, R., Colangelo, G., Ferrini, F., Salbitano, F., ... Sanesi, G. (2015). Go greener, feel better? The positive effects of biodiversity on the well-being of individuals visiting urban and peri-urban green areas. Landscape and Urban Planning, 134, 221-228. https://doi.org/10.1016/j.landurbplan.2014.10.022

Cohen-Shacham, E., Walters, G., Janzen, C., \& Maginnis, S. (2016). Nature-based Solutions to address global societal challenges. Gland, Switzerland: IUCN. https:// doi.org/http://dx.doi.org/10.2305/IUCN.CH.2016.13.en 
Cormier, N. S., \& Pellegrino, P. R. M. (2008). Infra-Estrutura Verde : Uma Estratégia Paisagística Para a Água Urbana Green Infrastructure : a Natural Systems Approach To Stormwater in. Paisagem E Ambiente: Ensaios, 25, 127-142.

Donovan, G. H., \& Prestemon, J. P. (2012). The effect of trees on crime in Portland, Oregon. Environment and Behavior, 44(1), 3-30. https://doi. org/10.1177/0013916510383238

Driessnack, M. (2009). Response to Intervention. Journal for Specialists in Pediatric Nursing, 14(3), 73-75. https://doi.org/10.1598/RT.64.5.10

Escobedo, F. J., Giannico, V., Jim, C. Y., Sanesi, G., \& Lafortezza, R. (2019). Urban Forestry \& Urban Greening Urban forests, ecosystem services, green infrastructure and nature-based solutions: Nexus or evolving metaphors ? $\square$. Urban Forestry \& Urban Greening, 37(March 2018), 3-12. https://doi.org/10.1016/j.ufug. 2018.02.011

Foster, J., Lowe, A., \& Winkelman, S. (2011). THE VALUE OF GREEN INFRASTRUCTURE The Center for Clean Air Policy. The Center for Clean Air Policy. New York.

Fraga, R. G. (2020). Soluções baseadas na Natureza : elementos para a tradução do conceito às políticas públicas brasileiras. Universidade de Brasília.

Gilstad-Hayden, K., Wallace, L. R., Carroll-Scott, A., Meyer, S. R., Barbo, S., Murphy-Dunning, C., \& Ickovics, J. R. (2015). Research note: Greater tree canopy cover is associated with lower rates of both violent and property crime in New Haven, CT. Landscape and Urban Planning, 143, 248-253. https://doi.org/10.1016/j. landurbplan.2015.08.005

Herzog, C., \& Rozado, C. A. (2019). Diálogo Setorial UE-Brasil sobre soluções baseadas na natureza. Bruxelas. https://doi.org/10.2777/698847

IBGE. Instituto Brasileiro de Geografia e Estatística. (2017). Classificação e caracterização dos espaços rurais e urbanos do Brasil : uma primeira aproximação. Coordenação de Geografia. Retrieved from http://biblioteca.ibge.gov.br/visualizacao/ livros/liv100643. pdf\%0Ahttp://www.ibge.gov.br/home/geociencias/geografia/ espacos_rurais_e_urbanos/default.shtm

Instituto Polis. (2021). E REVISÃO. Brasília.

Kaplan, R. (1993). The role of nature in the context of the workplace. Landscape and Urban Planning, 26(1-4), 193-201. https://doi.org/10.1016/0169-2046(93)90016-7

Lafortezza, R., \& Sanesi, G. (2020). Nature-based solutions : Settling the issue of sustainable urbanization. Environmental Research, 172(December 2018), 394-398. https://doi.org/10.1016/j.envres.2018.12.063

Lima, M. C. P. B. de, \& Schenk, L. B. M. (2018). ESTUDO DE INFRAESTRUTURA VERDE NA BACIA HIDROGRÁFICA DO CÓRREGO MONJOLINHO, SÃO CARLOS, SP. Revista LABVERDE, 9(1), 50. https://doi.org/10.11606/issn.2179-2275.v9i1p50-72

Liu, Q., Zhang, Y., Lin, Y., You, D., Zhang, W., Huang, Q., ... Lan, S. (2018). The relationship between self-rated naturalness of university green space and students' restoration and health. Urban Forestry and Urban Greening, 34(June), 259-268. https://doi.org/10.1016/j.ufug.2018.07.008

Macedo, S. S., Queiroga, E. F., Galender, F. C., \& Degreas, H. (2012). Os Sistema de Espaços Livres na Constituição da Forma Urbana Contemporanea no Brasil. Paisagem Ambiente: Ensaios, (30), 137-172. 
Macedo, L. S. V. de, Picavet, M. E. B., Oliveira, A. P. de, \& Shih, W. (2021). Urban green and blue infrastructure : A critical analysis of research on developing countries, 313(June). https://doi.org/10.1016/j.jclepro.2021.127898

Magnoli, M. M. (2006). O parque no desenho urbano parks and urban design. Paisagem Ambiente: Ensaios, 21, 199-214.

Mullaney, J., Lucke, T., \& Trueman, S. J. (2015). A review of benefits and challenges in growing street trees in paved urban environments. Landscape and Urban Planning, 134, 157-166. https://doi.org/10.1016/j.landurbplan.2014.10.013

Peres, R. B. (2012). O Planejamento Regional e Urbano e a Questão Ambiental: Análise da relação entre o Plano de Bacia Hidrográfica Tietê-Jacaré e os Planos Diretores Municipais de Araraquara e São Carlos, SP. Universidade Federal de São Carlos.

Peres, R. B., Bongiovanni, L., \& Schenk, M. (2021). Planejamento da paisagem e mudanças climáticas : uma abordagem multidisciplinar em São Carlos ( SP ), 24.

Peres, R. B., Silva, S. R. M. \& Schenk, L. B. M. (2019). Paisagem urbana, espaços públicos e a gestão territorial em cidades médias paulistas: reflexões a partir de São Carlos, SP, Brasil. Terr@Plural, 13(3), 141-164. https://doi.org/10.5212/ TerraPlural.v.13i3.0011

Rhodes, J. R., Ng, C. F., de Villiers, D. L., Preece, H. J., McAlpine, C. A., \& Possingham, H. P. (2011). Using integrated population modelling to quantify the implications of multiple threatening processes for a rapidly declining population. Biological Conservation, 144(3), 1081-1088. https://doi.org/10.1016/j. biocon.2010.12.027

Santos, Maria Fernanda Nóbrega Enokibara, M. (2021). INFRAESTRUTURA VERDE : CONCEITOS, TIPOLOGIAS E TERMINOLOGIA NO BRASIL. Paisagem Ambiente Ensaios, 32(47), 1-15.

Schenk, L. B. M., Peres, R., \& Fantin, M. (2018). Sistema de espaços livres e sua relação com os agentes públicos e privados na produção da forma urbana de São Carlos. In Quadro geral da forma e do sistema de espaços livres das cidades brasileiras. FAU/USP. Retrieved from https://www.dropbox.com/s/7kkcd5gc4a92uy2/ LIVRO 3 - Quadro geral da forma e do sistema de espaços livres das cidades brasileiras_20-07.pdf?dl=0 PP - São Paulo

Schutzer, J. G. (2014, June). INFRAESTRUTURA VERDE NO CONTEXTO DA INFRAESTRUTURA AMBIENTAL URBANA E DA GESTÃO DO MEIO AMBIENTE. Revista LabVerde, 13-30.

Sposito, E. S. Mercado de trabalho no Brasil e no Estado de São Paulo (0226). In: SPOSITO, Eliseu S.; SPOSITO, Maria Encarnação Beltrão; SOBARZO, Oscar. (Orgs.) Cidades médias: produção do espaço urbano e regional. São Paulo: Expressão Popular. 29-46.

Silva, R. T., \& Porto, M. F. do A. (2003). Gestão urbana e gestão das águas: caminhos da integração. Estudos Avançados, 17(47), 129-145.

Townsend, J. B., \& Barton, S. (2018). The impact of ancient tree form on modern landscape preferences. Urban Forestry and Urban Greening, 34(February), 205-216. https://doi.org/10.1016/j.ufug.2018.06.004

Trevisan, D. P., Moschini, L. E., \& Balzter, H. (2018). Revista Brasileira de Geografia Física. Revista Brasileira de Geografia Física, 5(11), 1819-1831. 
Troy, A., Morgan Grove, J., \& O’Neil-Dunne, J. (2012). The relationship between tree canopy and crime rates across an urban-rural gradient in the greater Baltimore region. Landscape and Urban Planning, 106(3), 262-270. https://doi.org/10.1016/j. landurbplan.2012.03.010

van Dillen, S. M. E., de Vries, S., Groenewegen, P. P., \& Spreeuwenberg, P. (2012). Greenspace in urban neighbourhoods and residents' health: Adding quality to quantity. Journal of Epidemiology and Community Health, 66(6), 1-5. https://doi. org/10.1136/jech.2009.104695

Viana, S. M. (2013). Percepção e quantificação das árvores na área urbana do município de São Carlos, SP. Universidade de São Paulo Escola Superior de Agricultura "Luiz de Queiroz."

Wolfe, M. K., \& Mennis, J. (2012). Does vegetation encourage or suppress urban crime? Evidence from Philadelphia, PA. Landscape and Urban Planning, 108(2-4), 112-122. https://doi.org/10.1016/j.landurbplan.2012.08.006

Zhao, J., Chen, S., Jiang, B., Ren, Y., Wang, H., Vause, J., \& Yu, H. (2013). Science of the Total Environment Temporal trend of green space coverage in China and its relationship with urbanization over the last two decades. Science of the Total Environment, The, 442, 455-465. https://doi.org/10.1016/j.scitotenv.2012.10.014

Solutions to address global societal challenges. Gland, Switzerland: IUCN. https:// doi.org/http://dx.doi.org/10.2305/IUCN.CH.2016.13.en

Cormier, N. S., \& Pellegrino, P. R. M. (2008). Infra-Estrutura Verde : Uma Estratégia Paisagística Para a Água Urbana Green Infrastructure : a Natural Systems Approach To Stormwater in. Paisagem E Ambiente: Ensaios, 25, 127-142.

Escobedo, F. J., Giannico, V., Jim, C. Y., Sanesi, G., \& Lafortezza, R. (2019). Urban Forestry \& Urban Greening Urban forests, ecosystem services, green infrastructure and nature-based solutions: Nexus or evolving metaphors?. Urban Forestry \& Urban Greening, 37(March 2018), 3-12. https://doi.org/10.1016/j.ufug.2018.02.011

Fraga, R. G. (2020). Soluções baseadas na Natureza : elementos para a tradução do conceito às políticas públicas brasileiras. Universidade de Brasília.

Gilstad-Hayden, K., Wallace, L. R., Carroll-Scott, A., Meyer, S. R., Barbo, S., Murphy-Dunning, C., \& Ickovics, J. R. (2015). Research note: Greater tree canopy cover is associated with lower rates of both violent and property crime in New Haven, CT. Landscape and Urban Planning, 143, 248-253. https://doi.org/10.1016/j. landurbplan.2015.08.005

Herzog, C., \& Rozado, C. A. (2019). Diálogo Setorial UE-Brasil sobre soluções baseadas na natureza. Bruxelas. https://doi.org/10.2777/698847

IBGE. Instituto Brasileiro de Geografia e Estatística. (2017). Classificação e caracterização dos espaços rurais e urbanos do Brasil : uma primeira aproximação. Coordenação de Geografia. Retrieved from http://biblioteca.ibge.gov.br/visualizacao/ livros/liv100643.pdf\%0Ahttp://www.ibge.gov.br/home/geociencias/geografia/ espacos_rurais_e_urbanos/default.shtm

IPCC. (2020). Climate Change and Land: An IPCC Special Report on climate change, desertification, land degradation, sustainable land management, food security, and greenhouse gas fluxes in terrestrial ecosystems. (I. P. on C. Change, Ed.). Retrieved from https://www.ipcc.ch/srccl

Lafortezza, R. , \& Sanesi, G. (2020). Nature-based solutions : Settling the issue of 
sustainable urbanization. Environmental Research, 172(December 2018), 394-398. https://doi.org/10.1016/j.envres.2018.12.063

Lima, M. C. P. B. de, \& Schenk, L. B. M. (2018). ESTUDO DE INFRAESTRUTURA VERDE NA BACIA HIDROGRÁFICA DO CÓRREGO MONJOLINHO, SÃO CARLOS, SP. Revista LABVERDE, 9(1), 50. https://doi.org/10.11606/issn.2179-2275.v9i1p50-72

Liu, Q., Zhang, Y., Lin, Y., You, D., Zhang, W., Huang, Q., ... Lan, S. (2018). The relationship between self-rated naturalness of university green space and students' restoration and health. Urban Forestry and Urban Greening, 34(June), 259-268. https://doi.org/10.1016/j.ufug.2018.07.008

Macedo, S. S., Queiroga, E. F., Galender, F. C., \& Degreas, H. (2012). Os Sistema de Espaços Livres na Constituição da Forma Urbana Contemporanea no Brasil. Paisagem Ambiente: Ensaios, (30), 137-172.

Macedo, L. S. V. de, Picavet, M. E. B., Oliveira, A. P. de, \& Shih, W. (2021). Urban green and blue infrastructure : A critical analysis of research on developing countries, 313(June). https://doi.org/10.1016/j.jclepro.2021.127898

Magnoli, M. M. (2006). O parque no desenho urbano parks and urban design. Paisagem Ambiente: Ensaios, 21, 199-214.

Mcharg, I. (2020). Proyectar con la naturaleza. Traduzido da edição de 1992. Barcelona: G. Gili.

Mullaney, J., Lucke, T., \& Trueman, S. J. (2015). A review of benefits and challenges in growing street trees in paved urban environments. Landscape and Urban Planning, 134, 157-166. https://doi.org/10.1016/j.landurbplan.2014.10.013

Peres, R. B. (2012). O Planejamento Regional e Urbano e a Questão Ambiental: Análise da relação entre o Plano de Bacia Hidrográfica Tietê-Jacaré e os Planos Diretores Municipais de Araraquara e São Carlos, SP. Universidade Federal de São Carlos.

Peres, R. B., Bongiovanni, L., \& Schenk, M. (2021). Planejamento da paisagem e mudanças climáticas : uma abordagem multidisciplinar em São Carlos ( SP ), 24.

Peres, R. B., Silva, S. R. M., \& Schenk, L. B. M. (2019). Paisagem urbana, espaços públicos e a gestão territorial em cidades médias paulistas: reflexões a partir de São Carlos, SP, Brasil. Terr@Plural, 13(3),141-164. https://doi.org/10.5212/ TerraPlural.v.13i3.0011

Santos, Maria Fernanda Nóbrega dos Enokibara, S. M. (2021). INFRAESTRUTURA VERDE : CONCEITOS, TIPOLOGIAS E TERMINOLOGIA NO BRASIL Maria Fernanda Nóbrega dos Santos. Paisagem Ambiente Ensaios, 32(47), 1-15.

Schenk, L. B. M., Peres, R. , \& Fantin, M. (2018). Sistema de espaços livres e sua relação com os agentes públicos e privados na produção da forma urbana de São Carlos. In Quadro geral da forma e do sistema de espaços livres das cidades brasileiras. FAU/USP. Retrieved from https://www.dropbox.com/s/7kkcd5gc4a92uy2/ LIVRO 3 - Quadro geral da forma e do sistema de espaços livres das cidades brasileiras_20-07.pdf?dl=0 PP - São Paulo

Spirn, A. W. (1995). O Jardim de Granito. São Paulo: Edusp.

Townsend, J. B., \& Barton, S. (2018). The impact of ancient tree form on modern landscape preferences. Urban Forestry and Urban Greening, 34(February), 205-216. https://doi.org/10.1016/j.ufug.2018.06.004

TREE CITIES OF THE WORLD (20121). Disponível em: https://treecitiesoftheworld. 
org/tree-cities.cfm?chosen=BRA. Acessado em 07. Ago. 2021

Trevisan, D. P., Moschini, L. E., \& Balzter, H. (2018). Revista Brasileira de Geografia Física. Revista Brasileira de Geografia Física, 5(11), 1819-1831.

Viana, S. M. (2013). Percepção e quantificação das árvores na área urbana do município de São Carlos , SP. Universidade de São Paulo Escola Superior de Agricultura "Luiz de Queiroz."

Zhao, J., Chen, S., Jiang, B., Ren, Y., Wang, H., Vause, J. , \& Yu, H. (2013). Science of the Total Environment Temporal trend of green space coverage in China and its relationship with urbanization over the last two decades. Science of the Total Environment, The, 442, 455-465. https://doi.org/10.1016/j.scitotenv.2012.10.014

\section{AGRADECIMENTOS}

Os(as) autores(as) agradecem a todos os integrantes e colaboradores do Grupo de Trabalho de Planejamento dos Parques Urbanos de São Carlos (GTPU). 


\section{Daniel Tonelli Caiche}

Doutorado em Ciências Ambientais (Programa de Pós-graduação em Ciências Ambientais, Universidade Federal de São Carlos, 2020), Servidor público da Secretaria Municipal de Ciência, Tecnologia, Inovação e Meio Ambiente de São Carlos. dtcaiche@hotmail.com

ORCID: https://orcid.org/0000-0002-6503-3853

\section{Renata Bovo Peres}

Doutorado em Engenharia Urbana (Programa de Pós-graduação em Engenharia Urbana, Universidade Federal de São Carlos, 2012), Professora associada do Departamento de Ciência Ambientais da Universidade Federal de São Carlos.renataperes@ufscar.br

ORCID: https://orcid.org/0000-0002-5455-6667

\section{Luciana Bongiovanni Martins Schenk}

Luciana Bongiovanni Martins Schenk, Doutorado em Arquitetura e Urbanismo (Programa de Pós-graduação em Arquitetura e Urbanismo, Escola de Engenharia de São Carlos da Universidade de São Paulo, 2008), Professora Doutora do Instituto de Arquitetura e Urbanismo da Universidade de São Paulo, campus São Carlos. lucianas@sc.usp.br

ORCID: https://orcid.org/0000-0002-7944-7782

Recebido em: 09/08/2021.

Aceito em: 04/12/2021. 